\title{
The Potential Geographic Range of Pyrenophora semeniperda
}

\author{
Tania Yonow, Darren J. Kriticos, and Richard W. Medd
}

First author: Pest Risk Consultant, 34 Grand Vue Rd., Rotorua, 3201 New Zealand; second author: CSIRO Entomology, GPO Box 1700 Canberra, ACT 2601, Australia; and third author: NSW Agriculture, Orange Agricultural Institute, Forest Road, Orange, NSW 2800, Australia.

Current address of D. J. Kriticos: Forest Research, PB 3020, Rotorua, 3201 New Zealand.

Accepted for publication 4 March 2004.

\begin{abstract}
Yonow, T., Kriticos, D. J., and Medd, R. W. 2004. The potential geographic range of Pyrenophora semeniperda. Phytopathology 94:805-812.

There is no evidence that Pyrenophora semeniperda, the causal agent of leaf spotting in many annual and perennial grasses, currently occurs in Europe or Asia. However, there is potential phytosanitary concern that the importation of infected commodities could result in the introduction of this fungus into Eurasia, putting crops at risk and possibly resulting in economic losses. To assist in assessing the risk of geographic range extension of $P$. semeniperda, an analysis was undertaken to estimate the potential global distribution of this species, based on climatic suitability. Geographic distribution data for $P$. semeniperda in part of its current range were used to fit parameter values in a CLIMEX pest risk assessment model, and the remaining distribution data were used to validate the model. The CLIMEX model correctly predicts that virtually all locations where $P$. semeniperda has been found are climatically suitable. Only five

occurring during a favorable season and then dying out. Exploratory adjustments of the model to accommodate these records created unsatisfactory distortions in the projected climatic suitability surfaces, extending the suitable climatic zone beyond well-established traditional range boundaries. We are therefore confident that the model is credibly predicting the potential distribution of $P$. semeniperda worldwide. The CLIMEX model suggests that $P$. semeniperda could potentially extend its range throughout Europe and temperate regions of Asia, Africa, and South America. Our heavy reliance upon geographic data to build this CLIMEX model departs from most previous published examples in plant pathology, which have depended primarily upon experimentally derived physiological data to estimate model parameters. The use of geographic data to infer climate parameters is popular in CLIMEX models of weeds and arthropod pests and can provide decision-makers with early risk assessments of potential pathogen invasions, particularly where the pathogens have long, or difficult-to-study, lifecycles.
\end{abstract} locations worldwide where the fungus was recorded present are predicted as being unsuitable. These "outliers" may have been transient populations
Additional keywords: Drechslera campanulata, seedborne.
Pyrenophora semeniperda (Brittlebank \& Adam) Shoemaker (anamorph Drechslera campanulata (Lèv.) Sutton) is a fungal plant pathogen that infects seeds and causes leaf spotting in at least 36 genera of annual and perennial grasses, including winter cereal crops. Medd (14) provides a review of the host range and worldwide geographic distribution of $P$. semeniperda, which is updated in Medd et al. (16), and Medd and Jones (15) give a more detailed account of the species in Australia. Its current world distribution is mainly in temperate grasslands and winter cereal growing areas of Argentina, Australia, Canada, Egypt, New Zealand, South Africa, and the United States (Fig. 1) (8). Although originally recorded and described in France in the mid1800s (12), it has not since been recorded in Europe, and there are no known records from Asia. The reports from North and South America, South Africa, and New Zealand indicate that this fungus is found infrequently, and then generally at a low level $(1,6,16,18,21-23,28)$. The records from Argentina, Canada, South Africa, and New Zealand suggest the fungus has a limited distribution and host range in those countries. This was also the case for Australia (4) until targeted surveys of leaf spot diseases of grasses revealed the fungus to be widely distributed on a wide range of hosts, although its occurrence at any location is often sporadic and at a low level (15). While they may be widespread,

Corresponding author: D. J. Kriticos

E-mail address: darren. kriticos@forestresearch.co.nz

Publication no. P-2004-0601-01R

This article is in the public domain and not copyrightable. It may be freely reprinted with customary crediting of the source. The American Phytopathological Society, 2004 leaf spot lesions are mostly associated with early vegetative growth and seem not to affect grain yield potential (16).

Pyrenophora semeniperda appears to be a weak pathogen with no reports of significant economic damage from any country (16). However, the potential exists for $P$. semeniperda to extend its current range into new countries, particularly in Europe and Asia, through transportation of infected seed and grain. This paper reports an analysis undertaken to estimate the potential worldwide distribution of this fungus, based on ecoclimatic suitability.

The CLIMEX software package (CSIRO Publishing, Melbourne, Australia) $(25,26)$ is a popular method for undertaking risk assessments for arthropod pests, weeds, and diseases $(2,3,9,10,13$, $19,20,27)$. In comparison with other climate modeling programs, CLIMEX has the advantages that it includes a global meteorological database, and that its Compare Locations module is process-oriented. This means that it is relatively immune from the "novel climates" problem that confronts climate-matching and descriptive statistical models and which limits their ability to undertake global risk assessments (9). Scherm and Yang (20) pioneered the use of CLIMEX as a means of establishing the potential risk of invasion by a plant disease. In that study (20), they used experimentally derived estimates for climate response function parameters in CLIMEX, as did Ekins et al. (7). Brasier and Scott (3) combined the use of experimentally derived parameters with those inferred from geographic distribution data of the host species to develop a CLIMEX model for Phytophthora cinnamomi. In contrast, despite having access to a plethora of geographic information on the distribution of Magnaporthe grisea, the cause of rice blast disease, Lanoiselet et al. (11) did not attempt to develop an ecoclimatic model. Instead, they employed the simple Match 
Climates module in CLIMEX to derive an estimate of climatic similarity between a single site in the country of interest (Australia) and the locations elsewhere that were known to be suitable for $M$. grisea. The Match Climates module in CLIMEX should only be used when no other data is available (24).

In this paper, we attempt to identify those areas that are suitable for range expansion of $P$. semeniperda by modeling the potential global distribution of this species, based on climatic suitability. We rely primarily on the recorded geographic distribution of $P$. semeniperda to infer parameters in the CLIMEX Compare Locations module. Experimentally derived data are used to confirm that parameters are reasonable. This approach makes use of the rich information contained within the distribution data, avoids problems with attempting to compare instantaneous meteorological measurements obtained from laboratory recordings with longterm climatic averages, and also implicitly includes limitations due to the climatic preferences of hosts.

\section{MATERIALS AND METHODS}

The computer software program CLIMEX version $2.0(25,26)$ was used to estimate the potential worldwide geographic distribution of $P$. semeniperda in relation to its currently known geographic distribution (Fig. 1) and long-term average climate data. CLIMEX utilizes a database of meteorological climate station data, stored as monthly means, and interpolates this data down to weekly values. The meteorological database supplied with CLIMEX is based on a World Meteorological Organization (WMO) database. To make better use of the available geographic information, we employed a spatially interpolated ( 0.5 degree grid) meteorological data set provided by the Climate Research Unit (CRU) (17) and adapted for use in CLIMEX.

Although we noted discrepancies between the CRU meteorological database and the WMO database, we opted to use the CRU database for the reasons indicated previously. The crucial issue is that the model and the data set are internally consistent, i.e., the model is fitted to the same data set used for any predictions. A model created with either data set will produce unreliable results if applied to the other data set. Thus, if our model is to be applied to the WMO data set, then some parameters may need to be refitted.

Parameter fitting. Parameters were manually fitted to distribution data for $P$. semeniperda using the iterative adjustment-andcomparison method described in the CLIMEX manual (26). Parameter values were initially fitted to predict the known distribution of $P$. semeniperda in Australia, for which there is extensive past and recent survey information (14-16). It is worth noting that despite their broad appeal, generalized distribution maps such as those produced by the International Mycological Institute (8) are of limited use in this type of modeling compared with the point data that we used. When the predicted distribution in Australia was sufficiently well defined, records from North America (United States and Canada) were added to the analysis, and the model parameters were adjusted accordingly. Distribution data from North America were included in the model-fitting process on the grounds that these areas experience much lower extremes in winter temperatures than Australia, providing as broad a model training base as possible. Known distribution records outside North America and Australia were ignored during the model-fitting process but were used to validate the final model.

For the initial fitting of parameter values using the Australian distribution records, the meteorological data set provided with CLIMEX was used because model runs using this smaller data set were considerably faster than those using the CRU data set. Parameter values were then fine-tuned to fit the Australian distribution data using the CRU data set. The chosen values for the CLIMEX parameters are given in Table 1. The model was verified and adjusted for the United States and Canada using the CRU data set.

Pyrenophora semeniperda has a wide host range (14). Without undertaking extensive literature reviews on all of these hosts, it is impossible to assess whether any particular section of the range boundary of $P$. semeniperda is directly limited by climate, or indirectly by climatic limitations on the geographic range of its hosts, competitive exclusion, hyperparasitism, or other unknown causes. What we are inferring, therefore, is the climatic response of $P$. semeniperda within its ecological context. This means that the model parameters described below should be interpreted care-

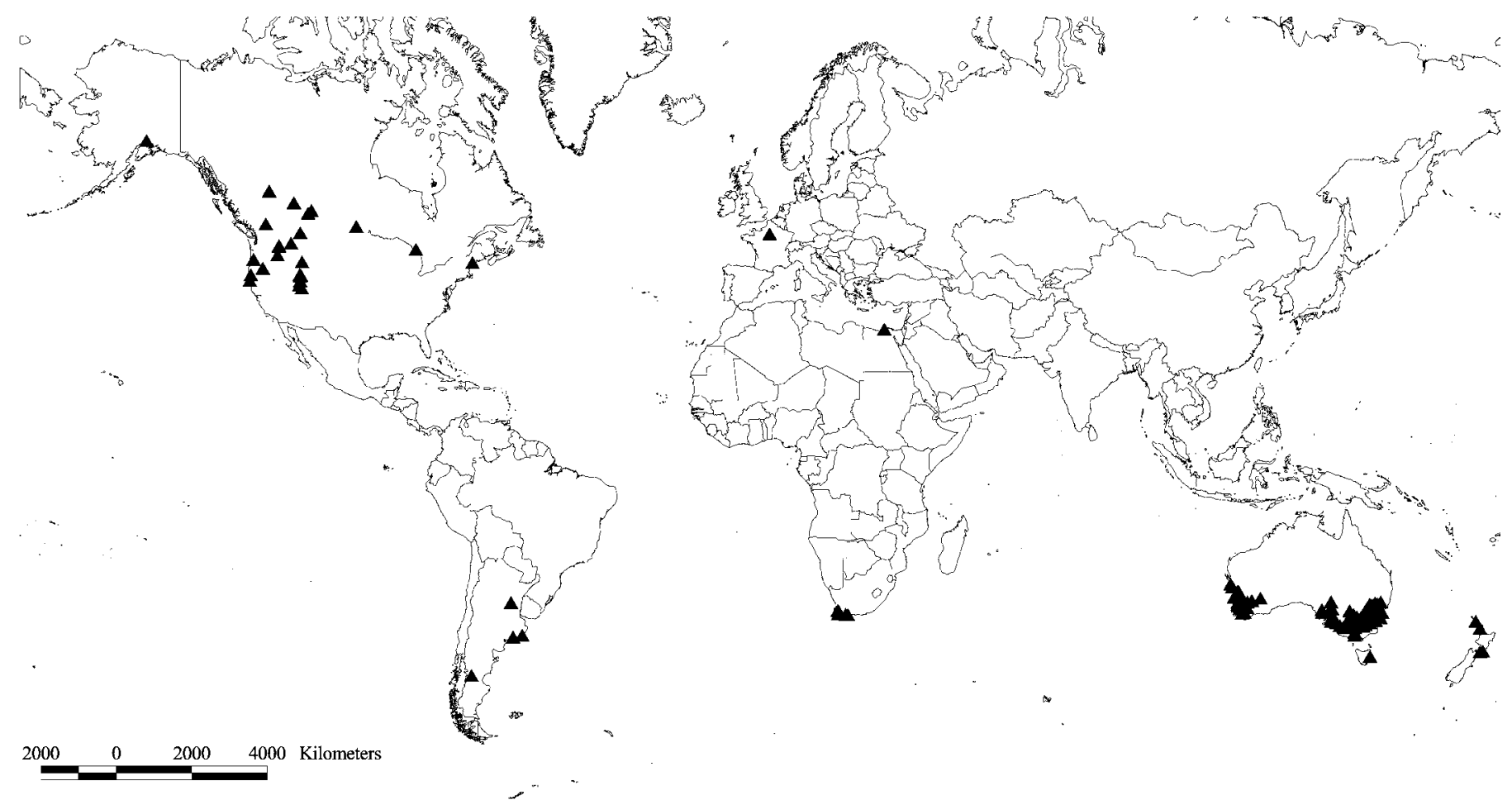

Fig. 1. Localities where Pyrenophora semeniperda has been recorded as occurring (15; R. W. Medd, unpublished data). 
fully because the biological meaning of some of the parameters may not be clear in the context of $P$. semeniperda.

Temperature parameters. Temperature parameters were initially based on information in Campbell and Medd (5) and Medd et al. (16). DV0 (lower temperature threshold for growth) was set to $5^{\circ} \mathrm{C}$, because low levels of germination, infection, and lesion production occur at this temperature. DV1 (lower optimum temperature for growth) and DV2 (upper optimum temperature for growth), set at 15 and $25^{\circ} \mathrm{C}$, respectively, were based on Figure 1 in Campbell and Medd (5). DV3 (upper temperature threshold for growth) was set at $28^{\circ} \mathrm{C}$. Although the fungus has been shown to grow and infect at $30^{\circ} \mathrm{C}$, it appears intolerant of higher temperatures. When DV3 was set at $30^{\circ} \mathrm{C}$, the model overpredicted the range in Australia into the subtropical region (data not shown), and so the value of this parameter was constrained to $28^{\circ} \mathrm{C}$. This discrepancy likely reflects the difference between instantaneous temperature measures used in laboratory studies and the longterm averages used in climate databases.

Moisture parameters. The moisture parameters were set to maximize the growth potential of $P$. semeniperda in the winterdominant rainfall regions where it occurs in Australia. In these regions, winter cereals are grown on current rainfall, as opposed to stored soil moisture accumulated from summer rainfall as in the subtropical grain-growing regions in northeastern Australia. The permanent wilting point of plants is generally near $10 \%$ soil moisture, and so the lower soil moisture threshold (SM0) of 0.2 reflects the need of $P$. semeniperda for more than the minimal amount of moisture to sustain its hosts' growth. The upper soil moisture threshold allows $P$. semeniperda to grow during run-off conditions, and the lower and upper optimum thresholds (SM1 and SM2) define a relatively broad, but wet, range of soil moisture conditions that should be optimal for the growth of this pathogen.

Heat stress. Heat stress helps to restrict the distribution of P. semeniperda to the more southerly parts of Australia. Because heat stress cannot logically accumulate within the temperature range suitable for growth, heat stress was set to accumulate as temperatures increase above DV3, the upper threshold for growth $\left(28^{\circ} \mathrm{C}\right)$. The rate accumulation parameter (THHS) was set to preclude the persistence of $P$. semeniperda in areas of western Australia, northern New South Wales, and southern Queensland that are outside the known range of the fungus.

Wet stress. As with heat stress, wet stress cannot occur below the upper soil moisture threshold for growth (SM3). Wet stress was thus set to occur when the soil moisture exceeds SM3 (1.3). With the selected accumulation rate of 0.007 per week, most areas of Australia that are affected by wet stress are also affected by the hot-wet stress interaction (described below). However, this accumulation rate means that some areas in southern Australia (a few locations on the southwest coast of western Australia, some locations in New South Wales and Victoria, and the west coast of Tasmania) experience wet stress without being affected by the hot-wet stress interaction.

Hot-wet stress. Hot-wet stress was used to limit $P$. semeniperda to its known range within areas of predominantly winter rainfall in Australia, and to preclude the suitability of subtropical regions of northern New South Wales and southern Queensland that have a summer-dominant rainfall pattern. Hot-wet stress also makes the coastal areas of Queensland and New South Wales unsuitable for $P$. semeniperda. The hot-wet stress accumulation rate was set so that when using the CRU meteorological database, P. semeniperda persisted at Quirindi, New South Wales $\left(150^{\circ} 39^{\prime} \mathrm{E}, 31^{\circ} 30^{\prime} \mathrm{S}\right)$, the most northerly location where it has been recorded in Australia.

Laboratory results of Campbell and Medd (5) show that low levels of germination of conidia and infection can occur at a dew temperature of $30^{\circ} \mathrm{C}$, which is both hot and wet, although both germination and infection levels are low if the dew period is short $(<3 \mathrm{~h})$. Thus, a combination of suitable temperatures and pro- longed moisture levels is necessary for establishment. These results would indicate that $P$. semeniperda should be able to persist in a subtropical environment. However, even though cereal crops are grown in northern New South Wales and southern Queensland, extensive surveys have failed to find P. semeniperda north of Quirindi. Host availability is clearly not limiting the northerly distribution of $P$. semeniperda, and there are no restricting physical barriers. Hot-wet stress was the only modeling mechanism that restricted the species' potential distribution in this zone. Similarly, hot-wet stress restricts the easterly extent of the suitable climatic zone in New South Wales where the rainfall pattern becomes more summer-dominant, and suitable hosts are also thought to occur.

There may in fact be a combination of factors that prevent $P$. semeniperda from expanding its range to northern and eastern New South Wales and southern Queensland. These could include unfavorable interactions of temperature, moisture, and the timing of the cereal crops, microbial species competition, or other unknown factors. A likely critical limitation is adequate dew periods in late winter/spring, given that the region experiences predominantly summer rainfall.

Degree-days per generation (PDD). The annual thermal accumulation (number of degree-days above DV0 $\left[5^{\circ} \mathrm{C}\right]$ ) necessary for $P$. semeniperda to complete a generation was adjusted to barely allow persistence at the coolest locations at which this species has been recorded in Canada (the one record from Alaska was considered an outlier). To calculate PDD, CLIMEX fits a sine function to the minimum and maximum temperatures, and then calculates the integral of the function above DV0 (26). The distribution data indicate that $P$. semeniperda is unable to persist in any area that does not experience $\geq 1,100$ degree-days above $5^{\circ} \mathrm{C}$ annually. The pathogen itself is likely to be able to complete its life cycle in less than the PDD value of 1,100 degree-days above $5^{\circ} \mathrm{C}$. However, the heat requirements for persistence of the pathogen include a period of physiological development on the part of its host prior to infection, as well as the heat requirements for completion of both host and pathogen life cycles.

Other stress functions. Stress functions in CLIMEX represent negative population growth. A species' distribution can be limited

TABLE 1. CLIMEX parameter values used to model ecoclimatic suitability for Pyrenophora semeniperda

\begin{tabular}{lll}
\hline Parameter & \multicolumn{1}{c}{ Description } & \multicolumn{1}{c}{ Value $^{\mathrm{a}}$} \\
\hline Temperature & & \\
DV0 & Lower temperature threshold for growth & $5^{\circ} \mathrm{C}$ \\
DV1 & Lower optimum temperature & $15^{\circ} \mathrm{C}$ \\
DV2 & Upper optimum temperature & $25^{\circ} \mathrm{C}$ \\
DV3 & Upper temperature threshold for growth & $28^{\circ} \mathrm{C}$ \\
Moisture & & \\
SM0 & Lower soil moisture threshold for growth & 0.2 \\
SM1 & Lower optimum soil moisture & 0.4 \\
SM2 & Upper optimum soil moisture & 0.8 \\
SM3 & Upper soil moisture threshold for growth & 1.3 \\
Heat stress & & \\
TTHS & Temperature threshold for heat stress & $28^{\circ} \mathrm{C}$ \\
THHS & Heat stress accumulation rate & 0.0005 week $^{-1}$ \\
Wet stress & & \\
SMWS & Soil moisture threshold for wet stress & 1.3 \\
HWS & Wet stress accumulation rate & 0.007 week $^{-1}$ \\
Hot-wet stress & & \\
TTHW & Temperature threshold for hot-wet stress & $23^{\circ} \mathrm{C}$ \\
MTHW & Soil moisture threshold for hot-wet stress & 0.2 \\
PHW & Hot-wet stress accumulation rate & 0.0101 week $^{-1}$ \\
PDD & Number of degree-days above DV0 & \\
& necessary to complete one generation & 1,100 degree-days $^{\mathrm{b}}$
\end{tabular}

\footnotetext{
${ }^{a}$ Values without units are dimensionless indices.

${ }^{\mathrm{b}}$ CLIMEX version 2.0 uses a different means of accumulating interaction stresses of previous versions of CLIMEX. PHW should be re-fitted prior to running this model in versions of CLIMEX prior to version 2.0.
} 
by an inability to grow sufficiently, or by stress accumulation. Pyrenophora semeniperda requires moderate temperatures and a prolonged period of moist conditions to support infection and the completion of its host's life cycle. These favorable climatic conditions can occur during the warmer or cooler season, depending upon the overall climatic pattern at the site, i.e., one location's summer may be similar to another location's winter. Pyrenophora semeniperda seems able to survive extremes of cold and dry conditions, because it is found in locations that experience these climates during the seasons that are unfavorable for growth. Therefore all cold and dry stress functions in CLIMEX were considered unnecessary in this analysis.

Model run and validation. The model was run on a worldwide scale using the CRU climate data. Almost all locations where the species has been recorded in Argentina, New Zealand, South Africa, and Egypt were indicated as climatically suitable. Minor discrepancies are discussed below.

\section{RESULTS}

Known world distribution. Figure 1 shows the recorded world distribution of $P$. semeniperda. It is mainly found in southern Australia, the northwestern United States, and southwestern Canada, but it has also been recorded in the eastern United States, northeastern and southwestern Argentina, southwestern South Africa and New Zealand, Egypt, and France (the original record). Records of locations where $P$. semeniperda has been searched for unsuccessfully were used in the parameter-fitting exercise, but have been omitted from these graphics for clarity.

Predicted potential distribution. The modeled ecoclimatic suitability worldwide for this species, using the parameter values from Table 1, is shown in detailed maps of Australia (Fig. 2), the Americas (Fig. 3), Africa (Fig. 4), and Europe and Asia (Fig. 5).

The predicted Australian distribution encompasses all but 3 of the 145 locations of recorded occurrence; these exceptions are detailed in the discussion below. A high percentage of the recorded locations fell within the high climatic suitability zone, especially in the southeast, and in the medium to high zones in the southwest of the continent. These areas experience Mediterranean or cool temperate climates and encompass the majority of the winter cropping regions of Australia. Significantly, the fungus has not been recorded in some of the high-rainfall maritime parts of southern mainland Australia or Tasmania, which are predicted as being of high climatic suitability.

As with Australia, the majority of the 28 locations of recorded occurrence in the Americas fell within the predicted zones, with one exception in Alaska and one in Argentina, which are discussed below. Large tracts of the Canadian Prairies and the United States around the Great Lakes are predicted to be highly suitable, yet there are few records of the fungus from these regions. The Northwest of the United States, where the majority of occurrence has been recorded, is predicted as having marginal or low suitability (Fig. 3).

Much of Africa is predicted as being unsuitable for the fungus apart from the southern regions of South Africa, an area in northwestern Namibia, patches in Kenya and Ethiopia, and a fringe of northern Africa bordering the Mediterranean Sea. The one record from Egypt falls within a zone predicted to be suitable, as do the few recorded occurrences in South Africa. However, southern parts of the Western and Eastern Cape Provinces extending into Lesotho, where the fungus has not been recorded, are predicted as being highly suitable (Fig. 4).

Much of western and eastern Europe, including the Iberian Peninsula, areas around the Baltic Sea, the Volgas and southern Urals and the Balkans, as well as southern Russia and some areas of the northern Far East are predicted as having medium or high climatic suitability (Fig. 5). Most of the Middle East, apart from regions adjoining the Mediterranean Sea in the west, the Indian sub-continent, and southeast Asia are predicted as being unsuitable. Apart from the original record describing the fungus more than 160 years ago, there are no recorded occurrences of the fungus in any of these regions.

\section{DISCUSSION}

The CLIMEX model closely agrees with the known geographic range of $P$. semeniperda and indicates that the pathogen is likely to be able to persist in both Mediterranean and cool temperate climates throughout the world. This potential range includes Europe, from which there have been no recent reports of its occurrence, and Asia, from which it has never been reported. There are no physical barriers known to be restricting the distribution of

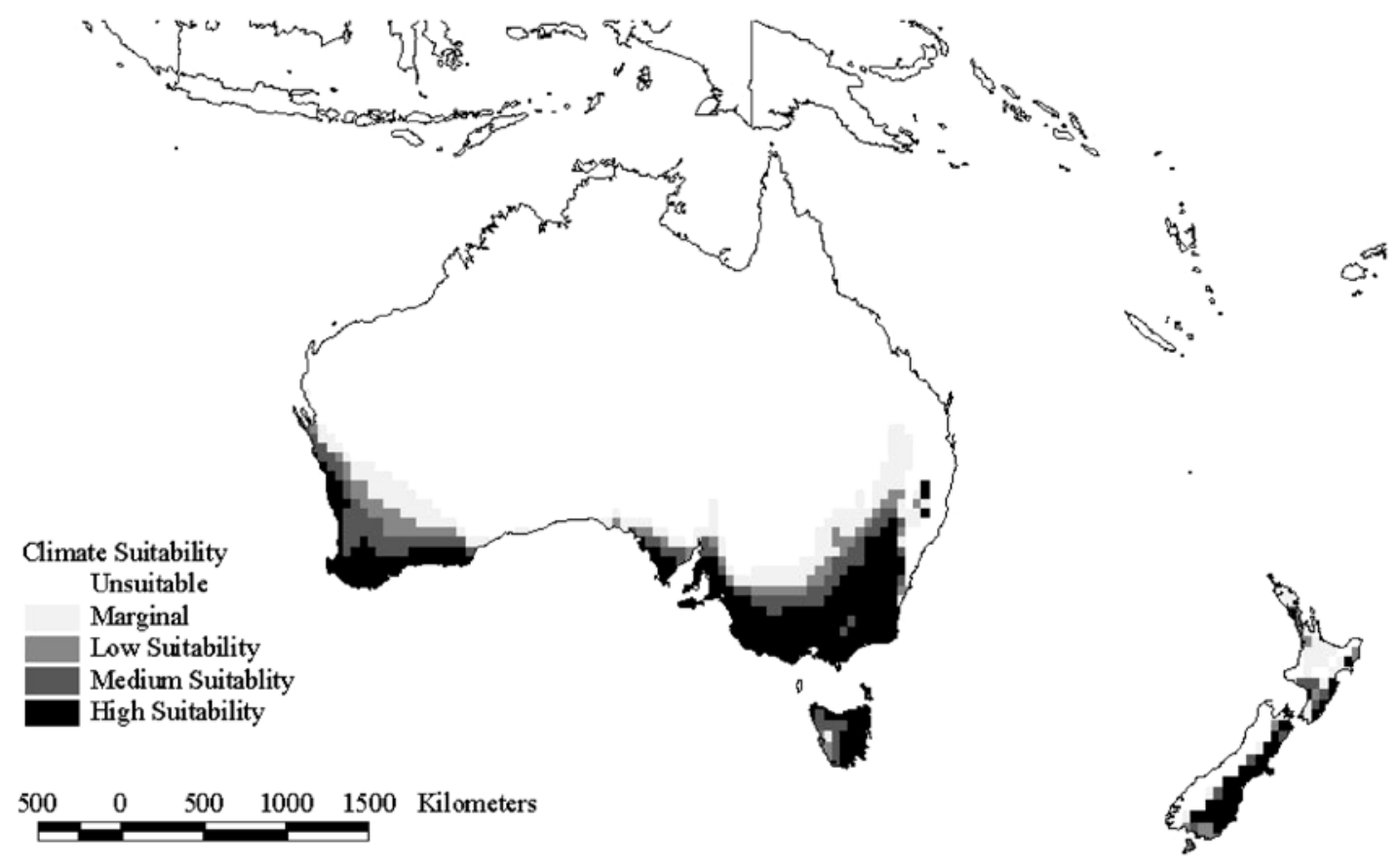

Fig. 2. Ecoclimatic suitability for Pyrenophora semeniperda in Australasia defined using CLIMEX with the parameter values from Table 1. 
$P$. semeniperda. As a seed pathogen, it can be spread by transportation of cereal grains or weed seeds that contaminate commodities such as grain and wool (5), and trade in grain commodities is an obvious potential invasion route.

Host availability does not appear to restrict the distribution of this pathogen. Pyrenophora semeniperda occurs on a broad range of annual and perennial grasses, including winter cereals. It has also been recorded on seeds of several dicotyledonous species (14). The fact that in Australia, P. semeniperda does not persist north of Quirindi in New South Wales, despite cereal hosts being available, indicates that hosts are not a limiting factor to range expansion of this fungus into regions with a summer-dominant rainfall pattern. While there are no known species of microorganisms able to competitively exclude $P$. semeniperda, it is possible that interactions or competition with other species may be limiting its expansion northward in Australia.

Since elsewhere in its range, $P$. semeniperda infects many plant species originating in the Old World, especially parts of the
Middle East where many of the grass weeds and cereal crops originated, it is also possible that a combination of factors, such as species interactions and cultural practices, preclude $P$. semeniperda from occurring in Europe and Asia. Although most of Europe is predicted to be climatically suitable for this species, $P$. semeniperda has not been recorded there following the original identification and description $(12,14)$.

Because parameter values were fitted to a subset (i.e., Australia and North America) of the total known distribution records worldwide, independent validation was possible by considering the remainder of locations where $P$. semeniperda has been recorded. These countries include New Zealand, Argentina, Egypt, and South Africa. Almost all of the recorded locations of occurrence fall within the predicted areas of suitability. Five records remain in areas predicted to be unsuitable.

Palmer, Alaska, United States $\left(61^{\circ} 37^{\prime} \mathrm{N}, 149^{\circ} 16^{\prime} \mathrm{W}\right)$. Although $P$. semeniperda was recorded here, there is insufficient information associated with this record to assess the nature of this

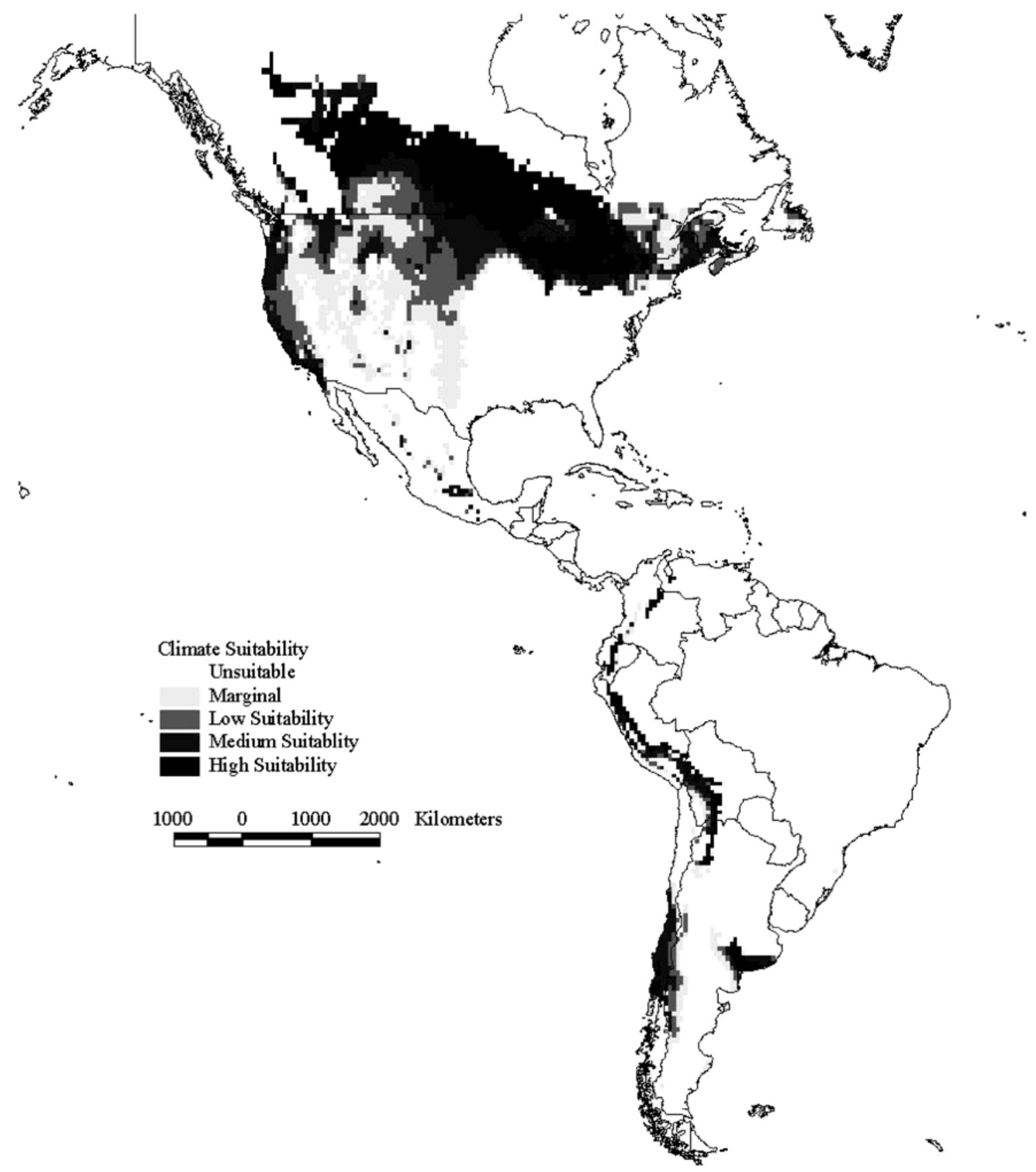

Fig. 3. Ecoclimatic suitability for Pyrenophora semeniperda in the Americas defined using CLIMEX with the parameter values from Table 1. 
incident. It is possible that inoculum was inadvertently introduced, resulting in a single infection episode. To simulate the persistence of $P$. semeniperda at this location, it would be necessary to reduce PDD from the current value of 1,100 to 600 . This increases the potential poleward range of $P$. semeniperda far beyond where it has been recorded, into mid-Alaska and far northern Canada and Russia. In the absence of any corroborating evidence, it seemed more reasonable to allow this location to remain unsuitable within the model than to change the PDD value and predict a much more extensive range for $P$. semeniperda.

Pooncarie, New South Wales, Australia (33'21'S, $\left.143^{\circ} 08^{\prime} \mathrm{E}\right)$. This location is considered unsuitable due to a lack of moisture. Pooncarie is considerably drier than the next driest locations at which $P$. semeniperda has been recorded. However, even a very

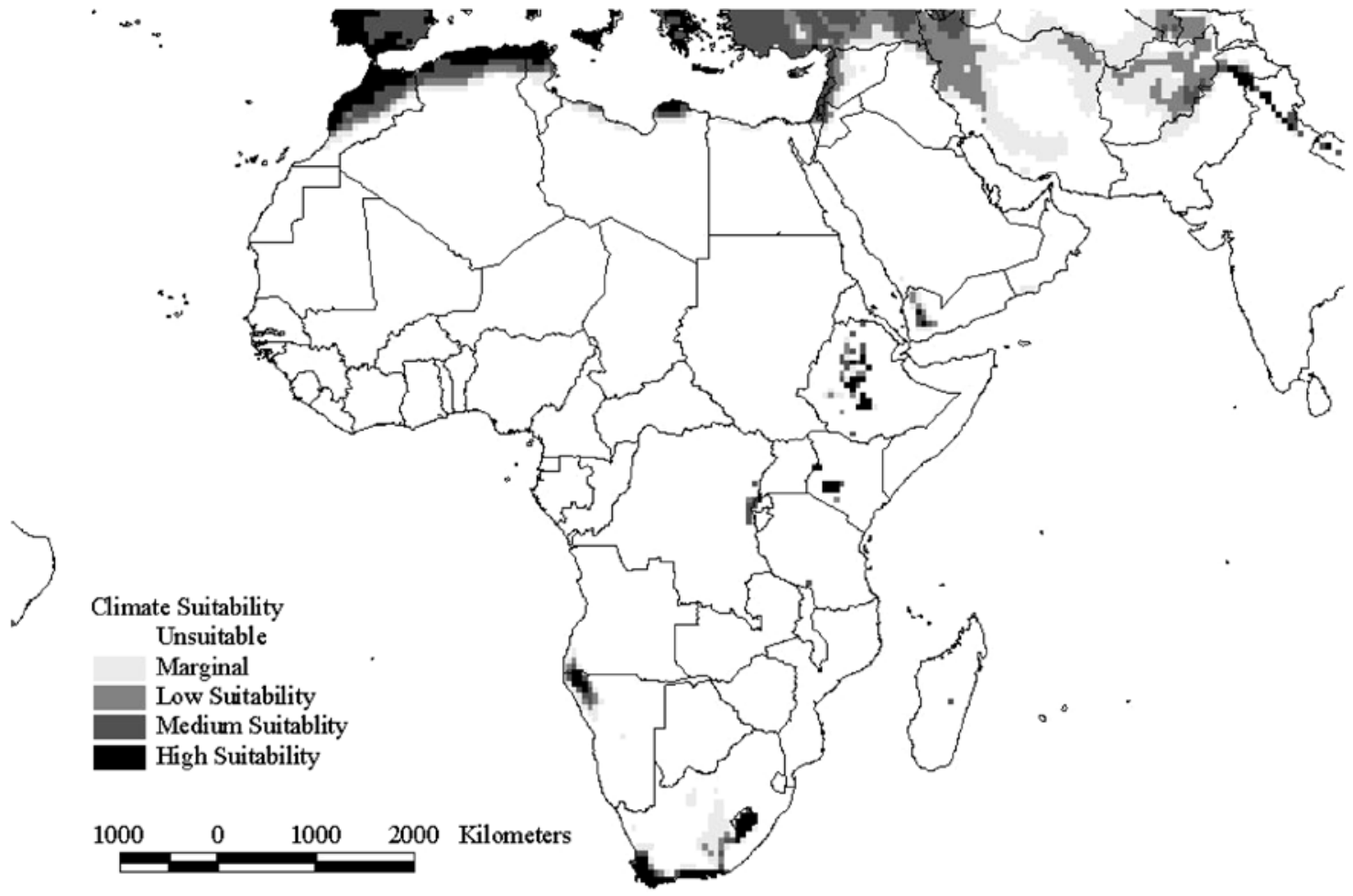

Fig. 4. Ecoclimatic suitability for Pyrenophora semeniperda in Africa defined using CLIMEX with the parameter values from Table 1.

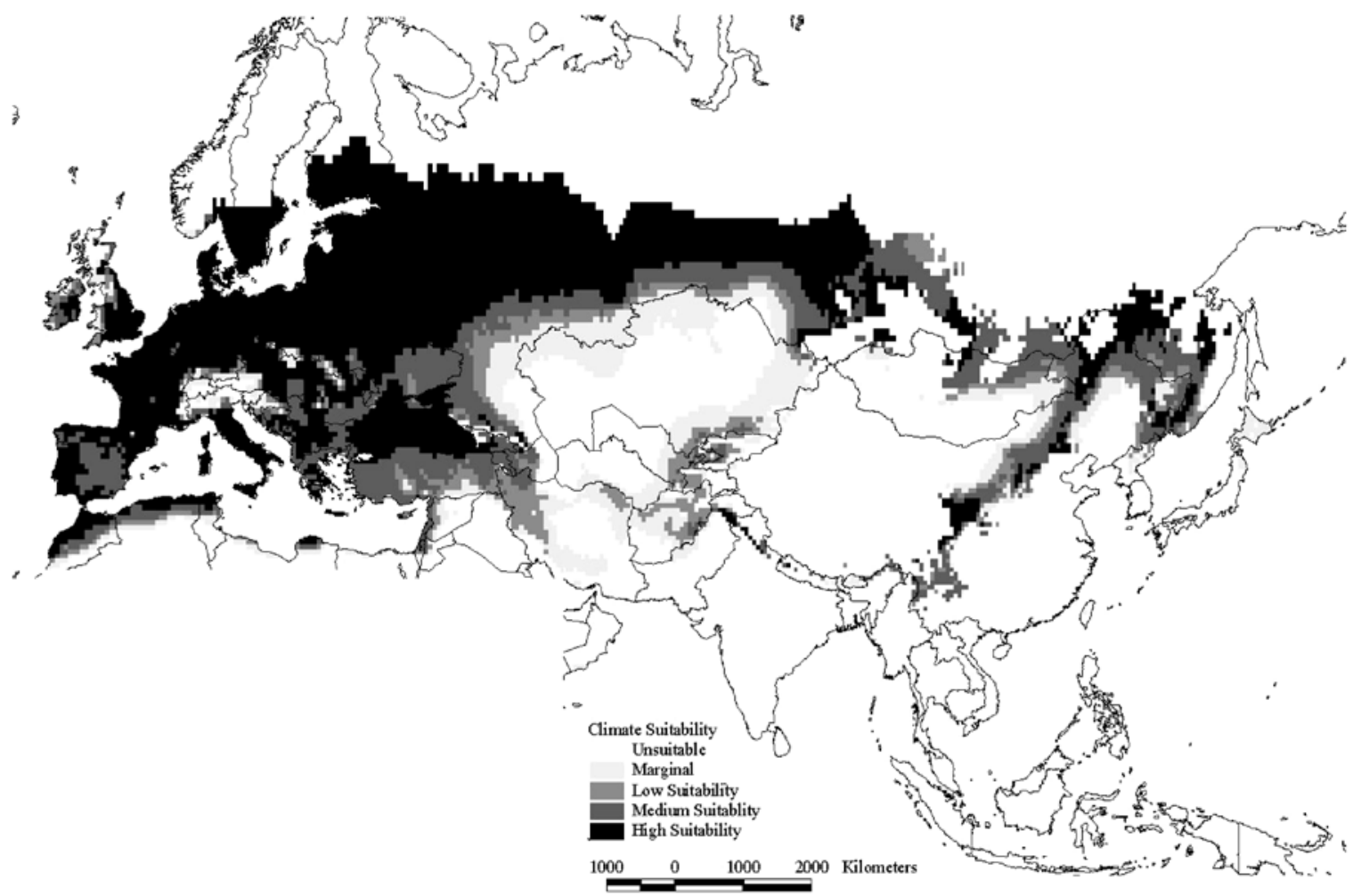

Fig. 5. Ecoclimatic suitability for Pyrenophora semeniperda in Europe and Asia defined using CLIMEX with the parameter values from Table 1. 
small amount of winter irrigation (e.g., top-up irrigation to make the total water available during winter, including any rainfall, equal to $7 \mathrm{~mm}$ per week) is sufficient to make this area marginally suitable for $P$. semeniperda. Without further information (e.g., whether infections occur regularly there, whether this incident was observed during a particularly wet winter or at a wet microsite, or whether irrigation is a common practice) it seemed more reasonable to allow Pooncarie to remain an outlier rather than to change the moisture parameters and allow the predicted range to extend into far drier locations.

Dural, New South Wales, Australia $\left(33^{\circ} 41^{\prime} \mathrm{S}, 151^{\circ} 00^{\prime} \mathrm{E}\right)$. $P$. semeniperda was recorded here on Pampas grass (Cortaderia sp.) at a horticultural establishment. The model indicates that the climate here provides considerable hot-wet stress. The nonmarginal nature of the modeled climate mismatch and the horticultural nature of the record location call into question the history of the host material, and make it unlikely that this location is within the natural climatic range of $P$. semeniperda.

Kenthurst, New South Wales, Australia $\left(33^{\circ} 39^{\prime} \mathrm{S}, 1_{151}^{\circ} 00^{\prime} \mathrm{E}\right)$. This record was also obtained on Pampas grass at a nursery. As with the nearby Dural record, the history of the host material is unknown, and it remains unlikely that the fungus occurs here naturally.

Paraná, Entre Rios, Argentina $\left(3^{\circ} 39^{\prime} \mathbf{S}, 6^{\circ} \mathbf{4 2}^{\prime} \mathrm{W}\right)$. This record falls within the wheat-growing region of Argentina, but on the fringe of a minor zone. It is predicted to be unsuitable due to extreme hot-wet stress. This area is climatically similar to the wheat-growing regions of southern Queensland, which are also unsuitable due to hot-wet stress. As with some of the other Argentinean records, this is a single record on grain without known history. It is therefore possible that the infection occurred in grain that may have originated elsewhere and was identified in grain tests at processing sites remote to the origin of the grain. Given that there are other records for Argentina, the fungus is undoubtedly established in this country, but as of yet there is no clearly defined geographic range. This is the only occurrence thus far recorded in a subtropical environment, and without further information on the occurrence and persistence of $P$. semeniperda there, the suitability of Paraná should be treated with caution.

All areas currently affected by $P$. semeniperda can be considered invasion source risks, particularly if there is movement of infected seed. There should be no seasonal differences in the risk, because infected or infested seeds can be transported at any time, although there may be a marginally higher level of risk if such seed is moved to a new location when the climatic conditions at the destination favor germination and growth.

The areas potentially at risk from this fungus can be identified from Figures 2 to 5 . To survive, it is necessary for the fungus to infect the seed of host species. Assuming that suitable hosts are not limiting, the extent of seed infection is governed by environmental conditions. For maximum seed infection, the duration of dew periods $(>48 \mathrm{~h}$ for wheat seed, optimally with an initial dark period of $18 \mathrm{~h}$ ), dew period temperatures (optimum of approximately $24^{\circ} \mathrm{C}$ for conidial germination and seed infection), and high inoculum concentrations (5) have been identified as critical limitations. Even in Australia where the fungus is widespread, conditions for seed infection are rarely optimal (5), which may partly explain why the fungus is of limited economic importance.

The CLIMEX model described in this paper relies strongly upon the use of geographic data on the occurrence of $P$. semeniperda. In this case, experimentally derived physiological and ecological data were used to provide a "reasonability check" on the parameter estimates. This approach is popular in models of weeds and arthropod pests $(9,10,13,27,29)$. Apart from Brasier and Scott's (3) use of geographic data from a host species to infer parameters for a pathogen model, this approach departs from previous published examples in plant pathology, which have depended primarily upon experimentally derived data to estimate the CLIMEX model parameters (7,20). Results will almost inevitably be different between the two methods. This potential range defined by the CLIMEX model is likely to be more restricted than that of a model based solely upon physiological responses derived in the laboratory. The advantages of our approach are twofold. Firstly, it avoids issues regarding discrepancies between experimentally derived instantaneous laboratory measurements and longterm climatic averages used for modeling. Secondly, geographic data may be more readily obtainable than experimental data for pathogens with long life cycles that are difficult to study, as is the case with many diseases of perennial plants.

\section{ACKNOWLEDGMENTS}

We thank R. Gilbert, H. Smith, S. Hetherington, and B. Auld for providing unpublished presence/absence data for $P$. semeniperda from recent surveys of leaf diseases on grasses in Australia; D. Pickering for updating worldwide herbaria records of the fungus; and $\mathrm{H}$. Scherm and an anonymous reviewer for providing useful comments on the manuscript. Financial assistance was provided by the Grains Research and Development Corporation of Australia, administered by Biosecurity Australia.

\section{LITERATURE CITED}

1. Barreto, D., and Fortugno, C. 1994. Drechslera verticillata: Cereal pathogen. INTA Argentina 25:71-79.

2. Brasier, C. M., Dreyer, E., and Aussenac, G. 1996. Phytophthora cinnamomi and oak decline in southern Europe. Environmental constraints including climate change. Ann. Sci. For. 53:347-358.

3. Brasier, C. M., and Scott, J. K. 1994. European oak declines and global warming: A theoretical assessment with special reference to the activity of Phytophthora cinnamomi. EPPO Bull. 24:221-232.

4. Brittlebank, C. C., and Adam, D. B. 1924. A new disease of the Gramineae: Pleosphaeria semeniperda nov. sp. Trans. Br. Mycol. Soc. 10:123-127.

5. Campbell, M. A., and Medd, R. W. 2003. Leaf, floret and seed infection of wheat by Pyrenophora semeniperda. Plant Pathol. 52:437-447.

6. Doidge, E. M. 1950. The South African fungi and lichens to the end of 1945. Bothalia 5:1-1094.

7. Ekins, M. G., Aitken, E. A. B., and Goulter, K. C. 2002. Carpogenic germination of Sclerotinia minor and potential distribution in Australia. Australas. Plant Pathol. 31:259-265.

8. International Mycological Institute. 1995. IMI Distribution Maps of Plant Diseases. CAB International, Wallingford, UK.

9. Kriticos, D. J., and Randall, R. P. 2001. A comparison of systems to analyze potential weed distributions. Pages 61-79 in: Weed Risk Assessment. R. H. Groves, F. D. Panetta, and J. Virtue, eds. CSIRO Publishing, Melbourne, Australia.

10. Kriticos, D. J., Sutherst, R. W., Brown, J. R., Adkins, S. W., and Maywald, G. F. 2003 Climate change and the potential distribution of Acacia nilotica ssp. nilotica in Australia. J. Appl. Ecol. 40:111-124.

11. Lanoiselet, V., Cother, E. J., and Ash, G. J. 2002. CLIMEX and DYMEX simulations of the potential occurrence of rice blast disease in southeastern Australia. Australas. Plant Pathol. 31:1-7.

12. Léveillé, J. H. 1841. Description de quelques espèces nouvelles de Champignons. Ann. Sci. Nat. 2 ser. 16:235-242.

13. Matsuki, M., Kay, M., Serin, J., Floyd, R., and Scott, J. K. 2001. Potential risk of accidental introduction of Asian gypsy moth (Lymantria dispar) to Australasia: Effects of climatic conditions and suitability of native plants. Agric. For. Entomol. 3:305-320.

14. Medd, R. W. 1992. A review of the world distribution and host range of Pyrenophora semeniperda. Rev. Plant Pathol. 71:891-901.

15. Medd, R. W., and Jones, K. H. 1992. Host range, distribution and imporance of the fungus Pyrenophora semeniperda (Brittlebank and Adam) Shoemaker (Ascomycotina: Pyrenomycetes) in Australia. Proc. Linn. Soc. NSW 113:15-26.

16. Medd, R. W., Murray, G. M., and Pickering, D. I. 2003. Review of the epidemiology and importance of Pyrenophora semeniperda. Aust. Plant Pathol. 32:539-550.

17. New, M. G., Hulme, M., and Jones, P. D. 1999. Representing 20th century space-time climate variability. I: Development of a 1961-1990 mean monthly terrestrial climatology. J. Climate 12:829-856.

18. O'Gara, P. J. 1915. A Podosporiella disease of germinating wheat. Phytopathology 5:323-325.

19. Reynaud, P. 2000. L'aleurode Bemisia tabaci en France. Situation actuelle et possibilités de developpement (Bemisia tabaci. Situation and possibilities of development in France). Phytoma 527:18-21. 
20. Scherm, H., and Yang, X. B. 1999. Risk assessment for sudden death syndrome of soybean in the north-central United States. Agric. Syst. 59:301-310.

21. Scott, D. B. 1988. Leaf spot diseases on small grain cereals in South Africa: Symptoms and causative fungi. Phytophylactica 20:77-81.

22. Sheridan, J. E. 1977. Drechslera spp. and other seed-borne pathogenic fungi in New Zealand cereals. N.Z. J. Agric. Res. 20:91-93.

23. Shoemaker, R. A. 1966. A pleomorphic parasite of cereal seeds, Pyrenophora semeniperda. Can. J. Bot. 44:1451-1456.

24. Sutherst, R. W. 2003. Prediction of species geographical ranges. Biogeography 30:805-816.

25. Sutherst, R. W., and Maywald, G. F. 1985. A computerized system for matching climates in ecology. Agric. Ecosyst. Environ. 13:281-299.
26. Sutherst, R. W., Maywald, G. F., Yonow, T., and Stevens, P. M. 1999. Predicting the Effects of Climate on Plants and Animals. CD-ROM and User Guide. CSIRO Publishing, Melbourne, Australia.

27. Vera, M. T., Rodriguez, R., Segura, D. F., Cladera, J. L., and Sutherst, R. W. 2002. Potential geographical distribution of the Mediterranean fruit fly, Ceratitus capitata (Diptera: Tephritidae), with emphasis on Argentina and Australia. Popul. Ecol. 31:10091022.

28. Wallace, H. A. H. 1959. A rare seed-borne disease of wheat caused by Podosporiella verticillata. Can. J. Bot. 37:509-515.

29. Yonow, T., and Sutherst, R. W. 1998. The geographical distribution of the Queensland Fruit Fly, Batrocera (Dacus) tryoni, in relation to climate. Aust. J. Agric. Res. 49:935-953. 